\title{
PRIVACY: ITS CONSTITUTION AND VICISSITUDES
}

\author{
EDWARd ShILs*
}

The idea of privacy is a vague one and difficult to get into a right perspective. Numerous meanings crowd in on the mind that tries to analyze privacy: the privacy of private property; privacy as a proprietary interest in name and image; privacy as the keeping of one's affairs to one's self; the privacy of the internal affairs of a voluntary association or of a business corporation; privacy as the physical absence of others who are unqualified by kinship, affection, or other attributes to be present; respect for privacy as respect for the desire of another person not to disclose or to have disclosed information about what he is doing or has done; the privacy of sexual and familial affairs; the desire for privacy as a desire not to be observed by another person or persons; the privacy of the private citizen in contrast with the public official; and these are only a few. But not only are there many usages of the concept of privacy; there are also the numerous related and contrasting terms: freedom, autonomy, publicity, secrecy, confidentiality, intimacy, and so forth. In the ensuing paragraphs, I will attempt to state a little more clearly what I mean by "privacy" and to place it in relationship to other concepts.

Privacy is a "zero-relationship" between two persons or two groups or between a group and a person. It is a "zero-relationship" in the sense that it is constituted by the absence of interaction or communication or perception within contexts in which such interaction, communication, or perception is practicable-i.e., within a common ecological situation, such as that arising from spatial contiguity or membership in a single embracing collectivity such as a family, a working group, and ultimately a whole society. Privacy may be the privacy of a single individual, it may be the privacy of two individuals, or it may be the privacy of three or numerous individuals. But it is always the privacy of those persons, single or plural, vis-à-vis other persons.

In any society, most of the population is private in a certain sense vis-à-vis most of the rest of the population. Mutual ignorance obtains; interaction is impossible because no structural or spatial context of interaction exists. But this separateness is not privacy in our sense. The phenomenon of privacy exists only in contexts in which interaction, communication, or perception is physically practicable and within the range of what can be expected of human beings. The situation must, therefore, be one in which the abrogation of privacy by intrusion from the outside or by renunciation from the inside is practically possible.

\footnotetext{
* Professor of Sociology and Social Thought, University of Chicago. Fellow of King's College, Cambridge.
} 
Thus, it is relevant to speak of privacy only where the isolation of a person or a group can be breached. It may be true that the personal private affairs of a factory worker in Chicago are unknown to a factory worker in Dallas; neither of them has ever encountered the other in any way or been a member of any common collectivity except American society. But it is not this kind of isolation-noninteraction, noncommunication, or nonperception-to which the term privacy refers. We speak of privacy only where there is a feasible alternative to privacy, namely, where actions or words can be either withheld or disclosed, where a space can be inviolate or intruded on, where a situation can be disregarded or observed. Thus privacy presupposes the prior existence of a system of interaction among persons in a common space-it might be face-to-face interaction within a household, a neighborhood, or village or within a unit in a corporate body such as a firm, an army, or a congregation; the presupposed system of interaction might be one in which there is ordinarily no face-to-face interaction between authority and subject within a corporate body like a large church, a large firm, a large army, or the state, and in which the interaction or perception is initiated by an agent of authority with the intention of intruding on the privacy of the subject.

What is privacy about? It is, for one thing, about information concerning the one person, the two persons, the three persons, etc. But what is the question concerning this information about which privacy might or might not exist? It is a matter of the possession and flow of information. We say that privacy exists where the persons whose actions engender or become the objects of information retain possession of that information, and any flow outward of that information from the persons to whom it refers (and who share it where more than one person is involved) occurs on the initiative of its possessors. This means that other persons do not come into possession of the information, they do not observe the actions that are the objects from which such information is generated, nor do they receive it from records (photographs, documents, or recordings) or from other persons who have observed the actions in question. Privacy in one of its aspects may therefore be defined as the existence of a boundary through which information does not flow from the persons who possess it to others. The actions of the former are not reported to, or observed or recorded or otherwise perceived by, the latter.

What is the decisive element in a breach of the boundary that defines the area of privacy? It is the acquisition or transmission of information without the voluntary consent or initiative of those whose actions and words generate the information. Where the latter disclose the information entirely voluntarily and on their own initiative, we speak of a sharing of privacy. Where the information is acquired by mánipulation, deception, coercion, or through a market mechanism, we speak of a 
disruption of or intrusion into privacy. Voluntariness on the part of the person or persons whose privacy is in question is an essential component. ${ }^{1}$

The information which is in question here refers to any events that occur in the private sphere. There are past and present relationships of personal affinity and hostility, of friendship and love and hatred, erotic relationships or practices, the primordial relationships of spouses, of parents and children, of siblings, of kinsmen, and of neighbors. The information might be about the internal affairs of private corporate bodies, the achievements, failures, and rewards of individuals in such bodies.

But is privacy only about "information"? What is private about the "private life" into which a previously "public figure" withdraws? What about private space, such as a building or a room or some other bounded area into which no one may enter without permission? What is private about "private property"? What is private about a person's face or body or bodily functions? What does the privacy of property share in common with the privacy of "life" or space or image or information? In all these usages, we refer to situations in which the individual or a group of individuals exercises control over resources that belong to them. The "private life" consists of the round of activities of one who does not hold public office or aspire to it." The private element in it is freedom with which the "private man" may manage his own resources, wealth, material goods, relationships, and so forth, without being answerable for what he does. He is not bound by the rules that govern public life; nor must he carry in the private sphere the responsibilities that are inherent in the public sphere. ${ }^{3}$ The "private life" is a secluded life, a life separated from the compelling burdens of public authority. "Private property" is property over which the private man freely exercises control; he may do so because it belongs to him.

"Private property," the "private life," and "private information" refer to relationships in which the individual or group of individuals retains "possession" of something that might otherwise be shared and that, if shared, is shared on the initiative of the "possessor." The nature of the "something" is less important than the retention of "possession." "Possession" means here the control over the movement of these properties across a boundary from person to person or from person to group or from group to group or from group to individual. Whatever the "something" is, it "belongs" to the individual or group of individuals. ${ }^{4}$ Individuals and groups of individuals have a

\footnotetext{
${ }^{1}$ It is at this point that it is pertinent to distinguish privacy from secrecy. Secrecy, too, involves information and boundaries affecting its flow. In secrecy, disclosure or acquisition beyond the boundary is prohibited, and the prohibition is attended by sanctions in event of a breach. In privacy, disclosure is at the discretion of the possessor, and such sanctions as laws provide are directed only against coercive acquisition by persons outside the boundary.

${ }^{2}$ It is worthwhile pointing out that until the nineteenth century in most of Europe and particularly in England, privacy meant a "private life," a life withdrawn from the governmental and civil arena. It referred also to the closely related phenomenon of "private ends," ends set by a "private person" on his own behalf. Only toward the latter part of the century did it come to refer to the privacy of information.

${ }^{3}$ In the private sphere, there are obligations too, but they are moral and not legal obligations.

" "Belongs" has long been the object of legal studies, but it has not been much analyzed by sociologists. The failure of sociologists to analyze the meaning of "belonging" arises, it appears, from the tendency
} 
substantive existence which is recognized by the consciousness that inheres in individual and in collective existence and that is acknowledged by those who have to deal with it. As such a substantive entity, self-locomoting, conscious, continuous, and conscious of its continuity, it generates and acquires properties (including "private property") and lays claim to possession of them.

Thus we see that the claim to the possession of "private property" is an instance of a more general class of claim to possession of a class of items more inclusive than material goods or human services. If the right to privacy is to be regarded as a "property right," then it is a right to a more general class of possession than "property right" as generally understood, and infringement on that right must not be regarded as assessable solely in the same terms as infringement on traditional property rightsfor example, infringement through trespass or theft. Rather the contrary; the latter are particular variants of infringements on a more general class of possessions.

Now what is contained in this general class of possessions? It is the class of all those things (words, movements, knowledge, states of mind, material objects, actions) which an individual or group of individuals generates, makes, or "acquires" through legitimate transactions. Possession of them entails right to their possession. The right naturally requires acknowledgment, but the category of possession is logically anterior to the claim and to the acknowledgment of the claim as a "rightful" claim.

The dispossession of these things which "belong" to individuals takes numerous forms. A man may be robbed of his physical property or the government may confiscate it. His "private life" may be constricted by obligatory military service, taxation, legal restraints on his style of life, labor legislation, and so forth.

The dispossession of what belongs to an individual cognitively likewise has many possibilities. What is comprised in these cognitive possessions? Relationships between persons, including acts of friendliness or hostility, relations of parents and children, the relationships of spouses, the relationships of siblings-in brief, most primordial and personal relationships-sexual relationships, conversations, consumption practices, most actions performed in private spaces. ${ }^{5}$ These cannot be taken away in the way in which physical property or claims to it can be taken away. They can, of course, be stopped or obstructed, but this is an interference with private liberty. ${ }^{6}$ What can be taken away is the knowledge of these actions.

of sociological analyses to "desubstantialize" individual and corporate existence into complexes of status and roles, into identities and images, into personalities as complexes of mechanisms. Yet the conception of "belongs" does not refer to what "belongs" to a role or a status. There is an individual or corporate substance, an entity which has a role, which has a status, a sense of its own identity.

5 These primordial and personal private actions (to which we shall refer henceforth as personal privacy) are not the only ones which can occur in privacy. Conversations about corporate actions, conversations about competitive educational and occupational performances in corporate bodies, conversations about public matters, may all occur in the private sphere, i.e., in private places and with other persons with whom a personal private relationship exists. But despite their context, they are not personal private matters in our sense and efforts to acquire possession of them will concern us only marginally.

As contrasted with public liberty. 
One of the simplest ways of acquiring possession is to interview the person and ask him questions directly or to lead him on through a series of questions to the point where he produces from memory what could not have been elicited immediately by a direct question. These are the procedures of policemen, prying acquaintances, sociological field workers, and psychoanalysts. The intrusions can occur also through unassented to or surreptitious acquisitions of images, documents, and records (electronic, written, and photographic) bearing on the private actions or being of the person intruded upon. This acquisition might involve the creation of new documents and records through the clandestine recording of conversations and clandestine photography or the taking possession of originals or copies of documents and records already existing in the possession of the person intruded upon.

Intrusion into the private physical, visual, or auditory space of another person can be a product of an action by an outsider which is partly assented to and partly coerced. A religious zealot insinuates himself across the threshold of a dwelling and then refuses to leave. The telephoning solicitor of commercial custom or the telephone interviewer, who, having got the subscriber to "answer" the ringing telephone, presses his listener to take some form of action or to answer certain questions, approximates a coercive entry into a private space. The clutter of postal advertising that falls through one's letter slot is clearly a coercive, if minor, intrusion. The noise of one's neighbor's television set that comes in through one's walls or windows is coercive, even if not so intended by the neighbor.

Much of the dispossession of private things is clandestine and coercive. The agent who enters one's house or hotel room in a person's absence and without his knowledge or assent and installs a recording or photographic or transmitting device is acting clandestinely and coercively. The government officer who computerizes all the government's data about particular individuals is acting clandestinely to intrude on the privacy of those individuals; he is creating a new image of the individuals without their knowing that he is doing so. A journalist who searches through public records (for example, divorce court records) to exhume some old facts about the personal affairs of a particular individual is intruding clandestinely on that individual's privacy.

Coercive intrusion need not be clandestine: A person who is tortured or otherwise deprived until he discloses previously undisclosed actions, which might be either private or public, ${ }^{8}$ knows that this is the intention of his torturer.

\footnotetext{
${ }^{7}$ There are some difficult decisions to be made about the boundary between the public and the private spheres. A crime, a trial on charge of a criminal action, and a sentence for a crime are clearly public actions. Yet, they seem to change their status as they recede into the past. They tend to become part of an individual's private sphere as if the crime has been expiated and if it is far enough in the past.

"Not all that is undisclosed is "private." Military and diplomatic secrets are undisclosed, but they are not private. They "belong" to the state and not to the individuals who share them. Embezzlement of funds from the government might be undisclosed by the embezzler, but the knowledge of the embezzlement does not "belong" to him any more than the money belongs to him.
} 
Manipulation of the person so that he discloses his personal private affairs, based as it is on deception, shares some of the properties of clandestine intrusion, but it does not involve physical intrusion and it has its points of departure in a voluntary action. Tests which the tester alleges are about one thing but which are intended to precipitate an unwitting disclosure of some state of mind or previously performed action are manipulative. "Subliminal advertising" is an intended clandestine intrusion into the private sphere of the individuals to whom it is directed.

In what follows we shall discuss intrusions on personal and primordial privacy above all, and deal with intrusions into corporate privacy only in the margin. We shall be concerned in part with the following questions: (I) How much privacy can a human being or group of human beings enjoy, given the fact of being born into and living in any society whatsoever? (2) How much privacy can be enjoyed by an individual or group of individuals, given the facts of existence in contemporary largescale industrialized urban societies? (3) To what extent do individuals or groups of individuals desire privacy?

\section{II}

Existence as a human being entails being under scrutiny. Those who would aid and nurture the infant could not do so if they could not observe it and receive from it a flow of information about its needs and desires. Once the child becomes mobile and acquires the capacity to communicate deliberately when it needs help, the complete observability of the child's movements is suspended. The child too begins to construct boundaries about itself. It uses its capacity to move to remove itself from the observation of its elders, to support the desire to be outside the range of the elders who exercise authority over him. The capacity for "keeping to one's self," to be unobserved, to withhold information about states of mind and actions, i.e., the capacity to retain possession of these emanations of the self and the desire to do so, all move in an upward curve for some time in the early life span of the individual. The physical and neural capacity and the desire for a discriminating control over the disclosure of information about the self continue to expand for some time. But it is not a unilinear function of age or physical strength. Quite apart from the level of desire, there are certain ineluctable conditions imposed by life in society that restrict the private possession of information about the self and about the groups to which the individual comes to adhere. Kinship constricts the privacy of the individual because it presents claims on him to be responsible for and to know about other members of the group and for them to know about him. Common residence makes him more observable, and absences raise questions that seek answers. Kinship establishes claims that intrude into the individual's private sphere, that demand information about actions and resources.

Just as there are spaces or places to which such information can be restricted, so 
there are public places where some of it is inevitably disclosed. Streets, workshops, places of assembly such as schools, theaters, meeting halls, public conveyances, are all loci of disclosure, where the individual cannot avoid some measure of observation. Very few individuals become hermits or recluses who never leave their "private places" to venture into the open. Heat and culture both force human beings into public places. The necessities of self-support by work in fields or workshops force human beings to be where others can see them and can overhear their conversations. Those who work in offices ordinarily have to share their space with others; those who are more elevated in the hierarchy of authority might have a private office, i.e., a space to themselves, but the necessities of collaboration force them outward. They must see others and be seen by them and therewith disclose something about themselves, even if the disclosure is involuntary.

The density of settlement and stability of residence put families and individuals into the presence of others and lay them open to the possibility of observation. It is impossible to avoid this scrutiny as long as visibility exists, which means as long as individuals must share certain common spaces. Visibility is the precondition and often the stimulus to curiosity.

It is not in the nature of human beings to be indifferent to their fellow men. The sight of any other human being arouses interest and the desire for some convivial contact; it also arouses repugnance, hatred, malevolent curiosity. It arouses, as the occasion calls for, affectionate sentiments, solicitude, fear. All of these entail some penetration into the area of the circle formed around the observed individual. (The boundary of the circle encloses the observed individual's past, his memories of his past, his relations with and sentiments about all persons other than the observer.)

Then there are the facts of authority. Those who rule, whether in the earthly or in the spiritual realms, wish to see their subjects and to know something about them. They might wish to know about their sins, large and small; they might wish to have them present in relatively public places such as churches, temples, or mosques. For the strength and welfare of the polity and the society, they might wish to know how much "property" they own and what income they receive from it; they might wish to know their names and numbers.

The need felt by rulers for the security of their own tenure and that of the regime means that they will, in varying degrees, seek to be informed about opinions which might have subversive effects. This too involves intermittent infringements of the privacy of individuals to discover whether they intend to perform actions disruptive of the public sphere.

Intensely sacred occasions demand the presence of those who form the collectivity -christenings, confirmations, marriages, family reunions, funerals. They deny the self-sufficiency of the individual and his right to absent himself. Collectivities the 
elites of which are convinced that they are in some way sacred or charismatic do not tolerate privacy among their members. They expect their adherents to be completely absorbed into the sacred and to withhold nothing. ${ }^{9}$

All this notwithstanding, no society can completely obliterate all privacy. There are walls which separate buildings, fences, hedges, blinds, and doors which offer some protection to the privacy of families. However, much life is lived in the open, there are some barriers, physical or social, that restrict the observability of the life of a family - or of an individual living alone and apart from a family. However much the authorities who control the state wish to penetrate into the lives of their subjects, both their curiosity and their capacities are limited. Even if they would, they cannot gain access to the life of everyone at all times; they cannot saturate the entire society with their observational activities. Nor, for that matter, do they wish to do so-even the elites of the most inquisitorial, absolutist regimes have not interested themselves in absolutely complete surveillance, partly because they have known that they did not have the power to accomplish it. The observations were made unequally.

The same has probably been true of gossip in traditional village communities and stable urban neighborhoods. Not everyone attracted equally the attention of the gossips and scandalmongers. It is likely that only certain families and individuals aroused curiosity to the point that information based on scattered observations was pooled, occasional observations subjected to intensive analyses, and questions raised as to their significance. The range of curiosity of the curious and prying is limited, and it is in any case not equally present in all persons. Some persons are more curious-others are more indifferent.

The separateness of places, the impenetrability of their physical boundaries, the limited curiosity of equals, and the limited powers of rulers, and indifference, have been the main bulwarks of that privacy which human beings have possessed or desired to possess through most of history. Changes in any of these affect the magnitude of the privacy that a society enjoys.

\section{III}

Let us turn now from these cursory remarks concerning the general limits on privacy and on intrusions into privacy and consider the position of privacy in modern urban societies. We will begin with European and North American societies in about the third quarter of the nineteenth century.

It has often been said by sociologists who have studied urban society that it freed men and women from the oppressive moral opinion of village and rural society. It increased indifference to most aspects of the behavior of most of one's fellow

\footnotetext{
- This is one of the reasons why the radical leaders of pre-19r 4 German Social Democracy were horrified by the "revisionist" view that Religion ist Privatsache.
} 
citizens; in so doing, it increased the amount of privacy that they enjoyed-by "amount," meaning the proportion of their total range of activity and thought that was disclosed only to those to whom the actor chose to disclose it. Indifference was, of course, fostered by large numbers and by residential and occupational mobility, which habituated human beings to a condition in which they could live in relative freedom from the scrutiny of others and could control the flow of information about themselves largely at their own discretion.

Why did indifference increase? It was not a function of a dulling of sensibility and sympathy; it was, rather, a consequence of the expansion and diversification of sensibility. The urban environment was more stimulating. Politics, culture, individual careers and ambitions, all drew attention out of the narrow primordial sphere and turned it outward, toward public things.

The deflection of attention was helped by a number of ecological changes whieh were associated with urbanization and industrialization. The diminishing significance of handicrafts and of agriculture, and the increasing proportion of the population employed in factories and offices, meant also an increasing proportion whose place of work and place of residence were made more distant from each other. The separation of place of residence from place of work, and the occasional change of place of residence, permitted and sometimes enforced by the rapid growth of cities and by the change in the character of districts within cities, meant that many persons lived only segmentally and for relatively short periods within the range of scrutiny of a given group of neighbors. There was too much else to do and too little time for the focusing and penetration of curiosity into the lives of neighboring families hidden behind thick walls, behind thick curtains and closed doors. Contacts between human beings became more segmented.

A greater element of voluntariness, arising out of personal affinity or affection, entered into life. Friendship and love took a somewhat larger place in the economy of human life and primordial compulsion a smaller place. Hence personal private matters came with greater frequency to be voluntarily shared, while indifference to those with whom such bonds did not exist resulted in a diminished curiosity and intrusiveness in the affairs of other families and individuals. Thus the privacy of personal and primordial relationships was furthered and sustained by the urban environment.

Alongside the basic ecological and economic changes, several other factors contributed to this efflorescence of privacy in the third quarter of the nineteenth century. One of these was the emergence of a conception of "respectability" among the urban working classes of the industrial countries. Ambition, frugality, sexual propriety, in orderly familial life, became ideals that were manifested in well-conducted households with sharply defined boundaries vis-à-vis neighboring families. "Scandalous" behavior was to be avoided; where it could not be avoided, it was regarded as im- 
perative that it be "hushed up" so that neighbors would not learn about it. The demand for and the practice of familial privacy were a common occurrence in the respectable working (and lower middle) classes. "Nosiness" was abhorred; the "nosy Parker" became the objection of revulsion.

A puritanical ethos gave another impetus to privacy. It not only emphasized each man's responsibility for his own soul and the well-being and propriety of his own family but also encouraged him to be ambitious. In doing so, it focused his attention on a remote goal and thereby diverted his attention from his neighbors. The womenfolk, who might not have been so ambitious and who were more domestically confined, were, however eager they might have been to penetrate into the affairs of their neighbors, correspondingly eager to seal off their families, to draw a boundary about their household, and to avoid the disclosure of domestic affairs. Ready though one might be to find out about one's neighbors, the unwillingness to allow one's neighbors to know about one's self made for discretion in informing neighbors and for care to prevent anything that might conceivably be derogatory from emerging beyond the walls of one's residence and garden. There was not just a preoccupation with the improvement of the status of one's family but an equal desire to avoid any action that might be injurious to the estimation in which the family held itself and wished to be held by others. There grew up, alongside and underlying these concerns, a sense of the inviolateness of what went on within the family.

The growth of individuality, the sense of one's identity as an individual, likewise supported the belief that one's actions and their history "belonged" to the self which generated them and were to be shared only with those with whom one wished to share them.

The situation had not always been like this. When men lived in villages over periods of many years they inevitably became well known to their fellow villagers. Small variations in public conduct could easily be interpreted as expressive of changes in that sphere of life which was not directly visible. Each man in a sense was the possession of his neighbors. It was difficult to escape the scrutiny and the imagination of others. Urbanization and industrialization changed this to a considerable degree-but, of course, not completely.

The growth of literacy and increased education, and the gradual involvement of larger and larger sections of the adult population in education and politics, extended the radius of attention. People did not cease to be interested in their neighbors; but they had to contend with the increased resistance of their neighbors to being known and with increased difficulties in knowing about them. Many more persons became interested in affairs more remote than the affairs of their neighbors. The intense desire to penetrate into the affairs of one's neighbors was probably attenuated by the increased interestingness of the affairs of the larger world. This made for a greater ease in the maintenance of privacy. 
The growth of religious sects in Protestant countries also fostered privacy because it added another element of heterogeneity to any given district. The attendance of the population of a particular district at a greater diversity of churches within that district further complicated the crisscrossing of lines of separation beyond what was necessarily entailed in the separation of place of residence from place of work.

On top of all this, governments became increasingly liberal and constitutional. The "night-watchman" state set as its goal the prevention of collisions among its citizens. The respect for private property that the state was concerned to enforce helped to stiffen a general regard for privacy, and the ethos of economic individualism worked in the same direction. The result of all these developments was a great increase in the amount of privacy.

Of course, privacy was not a totally new phenomenon in the history of human society, but the growth to predominance of the Northwestern European Protestant culture and its diffusion to the North American hemisphere and Australia meant also that civilization had shifted its center from Mediterranean and tropical climes, where much of life was lived out of doors. In societies in which heat, populousness, and poverty cause much of daily life to be lived out of doors and much of indoor domestic life to be lived in conditions of severe overcrowding of numerous persons into small spaces-into one or a few rooms-much more of life is visible than in colder climates and more prosperous countries. It is not that there is no sense of individual or familial privacy in these societies-there is in practically all societies-but rather that the limited physical or ecological opportunities for privacy are small, the culture prizes it less, and human beings do not demand it so much as they did in Western societies in the third quarter of the nineteenth century. In those latter societies, the ecological supports of privacy were stronger than they had ever been before, the economic and political systems favored it, the culture was congenial to it, and it became integral to the prevailing moral outlook. No class of persons except scattered and unorganized gossips had an interest in breaching the barriers which defined the privacy of individuals and groups.

What we have said above applies largely to the upper sections of the working classes, the middle classes, and the elites of the period in question. There was also a large unskilled working class, immigrant and native. Among these, families lived under very crowded conditions; many persons shared one room, many families shared common facilities such as water taps, toilets, and baths. There was little opportunity for individual or familial privacy. Much of their nonworking time, especially in summer, was spent on the streets. Local gin mills, saloons, cafes were the scenes of their leisure time. Most of their members probably regarded this as a normal condition, and only the most sensitive found it painful to bear. Awareness about the doings of one's neighbors, the gratification of impulses of curiosity about 
and malice toward them, were perhaps among the main pleasures available to the more respectable who did not go in for brawling and drunkenness.

But if the poorer sections of the working class had little privacy with respect to their neighbors, they were pretty well left alone by the public authorities. They had to divulge a little bit of information about their numbers, occupations, ages, and so forth, to the census. Except for very occasional interventions by the police in the event of a serious brawl or a murder, they were left alone by the government. Such limited social legislation as there was did not entail the collection of much information from them. In America, the immigrant quarters and the local professional politician were still only emerging; there was little of the "poor basket" charity which was later developed by philanthropists and ward politicians and which opened the private affairs of a family to outsiders. The mania of governments for information was still in a nascent state.

Finally, it should be pointed out that, even in the most industrialized and urbanized countries at this time, a great part of the population still lived from agriculture, either in villages or in the open country. In the latter, as throughout much of human history, corporate familial privacy was high, individual privacy was probably slight. In villages, there was much mutual scrutiny; tale bearers, scandalmongers, and chroniclers of disgrace and misfortune were well established. On the other hand, the isolation of villages from each other meant that if anyone did come into one from the outside, his past remained his own possession. Government was as uninquisitive in the countryside as it was in the great cities.

\section{IV}

Many changes took place in the half century that succeeded the "golden age of privacy." The trend toward industrialization and urbanization continued. Increasing prosperity and a higher standard of living afforded somewhat better housing conditions and therewith more individual privacy and more familial privacy as well. Occupational and residential mobility permitted and fostered escape from watchful eyes. The decreasing proportion of unskilled labor in the industrial working class meant an extension of the culture of "respectability." Thus, as far as the infringements on privacy by equals were concerned, the situation was rather like what it was in the earlier age.

But it is not only the practice of privacy by equals within a narrow radius that interests us here. Privacy is also affected by the activities of those who stand at the center of society, in positions of authority in political, administrative, and cultural institutions. Here a very considerable change in the situation of privacy occurred.

One of the ways of estimating the changed position of privacy since the golden age is to examine the development of those institutions at the center of society which regard it as their task to intrude on privacy. The main intruders from the center 
were popular journalism, private police and investigators, the specialists of personnel recruitment in large-scale private business, and the practitioners of psychological and, to a much smaller extent, sociological research. We shall deal with each of them briefly.

The spread of literacy into sectors of the population that did not seek education as part of their economic, political, cultural, and moral improvement meant a spatial extension of the range of attention of many persons without a corresponding enlargement of their interests into politics and culture. These persons, who were very numerous in the middle and working classes, became the fit audience of the popular press that came forward strongly at the end of the last century. The popular press attempted to satisfy the two sectors of the relatively recently literate populationthose who became interested in public political affairs, albeit in a simplifying manner; and the others, who were also attracted by the center of society but could not manage to divert their interests from the personally and familially private affairs of the center to its political aspect.

The fact that the popular press was able to consolidate its position among the large new literate public was evidence enough that the previous expansion of privacy did not represent a unilinear trend in the course of which the human race would divest itself more and more of its concern to intrude into the privacy of others. The very lengthening of the radius of attention made possible by literacy and education gave a new instrument to the desire to penetrate into the privacy of others. Frustrated as it was locally by the barriers of walls and doors and the very deeply rooted barrier thrown up by "respectability," the hunger to subject others who were more remote to one's own scrutiny found new stimulus and sustenance through the popular press.

There were two main objects of this desire to penetrate. The emergence of an incipient mass society at the beginning of the century was evident in the inclination among the peripheral strata to interest themselves in the center of society. The extension of the franchise, the development of the labor and socialist movements, impelled the attention of the more intelligent toward the working of the economic and political systems and the role of the ruling classes. The less intelligent also turned toward the center. They were enabled by the yellow press both to dwell among images of the center and to enjoy the remote and unilateral intimacy which that made possible. The carrying impulse was a rather primitively political one, a desire for knowledge of the scandalous doings of the mighty. This desire to know "scandalous things" about the mighty was a desire to be in proximity to the mighty, the famous, the glorious, the authoritative, and to derogate them at the same time. Affirmation and sacrilege were rendered simultaneously practicable by the activities of the new profession of popular journalism. The result was a new sector of the profession of journalism that regarded the penetration of the private sphere as its main occupa- 
tional task. It justified this penetration by reference to the satisfaction of popular desires and the freedom of the press unrestrainedly to enlighten the public.

This early stage of the development of mass society was also, as is well known, a period of exfoliation of revolutionary movements on the Continent of Europe. This had numerous repercussions in the United States and Great Britain as well as on the Continent, although neither of the former had a revolutionary movement of any consequence. Vague apprehensions and acute fears of bomb-throwing anarchists were a major feature of the upper and upper-middle class culture of the I8gos and the first decade of the present century. In the United States this was aggravated by the violence of the conflicts between industrialists and their employees. Special private police and detective services were established by employers as a means of coping with their dissatisfied workmen.

Secret police were not new; they are as old as empires. In France after the Restoration, secret police began to devote their attention to the "dangerous classes," the urban poor, who with the growth of industrialization on the Continent nurtured in their midst small revolutionary sects. A police speciality was the penetration of these sects through spies and informers, and so it continued throughout the century. The transfer of some of the personnel of these anarchist sects to the United States brought similar concerns and interests to the American police. The difference was that, in the United States, the governmental police-state and local-carried only a small proportion of the responsibility of surveillance and repression. Independent, privately organized bodies of policemen and investigators did the rest.

They performed not only the ordinary police functions of guarding property and supervising public places within and around industrial plants; they also performed "undercover operations," penetrating into organizations by pretending to be sympathetic devotees of the cause of the organization. They attempted by deception to learn about the affairs of the organizations and about the vulnerabilities of their leading members, such as dubious sexual practices, prison records, and so forth, which permitted them to be blackmailed into submission or discredited. The result was a "profession" of private investigators, experienced in illicit entry and observation, in deception, in acquiring and exploiting the confidence of a wide variety of persons for the purpose of gaining information about personal relationships and past histories.

Industrial police, "coal and iron police," "railway police," and private operatives came into existence on behalf of private property. They were the private property owners' means of self-help. Whereas in continental Europe such police were part of the state apparatus, in the United States they were to a substantial extent private enterprises. They were often established by former governmental police officials, and, once the pattern became established, their numbers multiplied. In Europe a police official could cease being an official only if he ceased being a policeman; in the United States this was not so. The characteristic American readiness to leave 
one career and the problematic status of public employment provided a perpetual source of "private operatives" ready to "shadow," impersonate, eavesdrop, wire-tap, and, in every other technologically feasible way, to penetrate into areas generally regarded as private.

The changes in the mores of Western Europe and America which made divorce more permissible, while the legal obstacles to it still remained, also contributed to the growth of the investigative profession. Jealous or suspicious spouses, or those already convinced of their partner's infidelity and now seeking legally valid grounds for divorce, came increasingly to seek the aid of private detectives to "shadow" and observe, to perform clandestine operations to obtain documents, photographs, and other evidence. Throughout both Catholic and Protestant Europe, such a profession existed; but partly because it was not reinforced by a numerous private industrial police, Europe did not come to know this large body of specialists eagerly offering their services in the infringement on all sorts of privacy for every purpose.

The establishment of a professional interest in the breaching of the boundaries of personal privacy was furthered by the simultaneous growth of mass-production industry based on semi-skilled labor and the growth of scientific academic psychology in the second and third decades of the present century. Employers, distrustful of their actual and potential employees, in whose capacity, loyalty, and honesty they had little confidence, were greatly attracted by the claims of psychology. The use of intelligence and vocational aptitude tests, which were first applied on a large scale for military purposes, helped to set the stage for the acceptance of "personality inventories." The concomitant growth of the profession of personnel management created another vested interest in the treatment of each potential employee both as an instrument of industrial efficiency without inherent dignity and as a potential enemy whose innermost aptitudes and propensities had to be disclosed and assessed, since neither his resourcefulness nor his loyalty could be counted on.

The distrust that employers felt for their employees was not just a product of the acute and often violent conflicts between employers and employees that were endemic in American industry in the thirty years preceding the First World War. It came also from the increase in the labor force employed in large commercial and industrial enterprises. The rapid growth and the recruitment of this new labor force was accompanied by high turnover rates. The large size of firms diminished opportunities for prolonged face-to-face contact between employers and their subordinates. Whereas previously an employee came into a smaller firm while young, after having served an extended apprenticeship under other employees of long-demonstrated capacity and loyalty, and with the expectation from both sides that, barring incompetence and depression, he would remain in the service of the firm indefinitely, the new candidate for employment came without this background or expectation. As long as firms were small and expanded slowly, a substantial number of the new 
employees might come from the family of one who was already an employee; that was another assurance to the employer of his reliability. A culture in which an employee remained in the service of the same firm for ten or twenty or thirty years or more was not one which impelled employers to seek supplementary means of ascertaining the skill or the moral reliability and fidelity of those whom they took into their enterprises.

But all these old conditions of employment became much rarer after the First World War. The employer ceased to know the men on his shop floor; the managers of great banks and insurance companies no longer knew their clerical employees. They came without any known and trusted sponsorship and the employers felt no assurance about either their skill, their zeal, their fidelity, or their honesty.

Psychology as a subject of research and teaching in American universities did not owe its intellectual origin to these developments in American economic and social structure. It was one of the numerous interests imported from Germany when American universities drew their inspiration from the universities of that country. But once it became established, it responded to the American situation. Aptitude and intelligence testing, the psychology of personnel or industrial psychology, soon found a place in the American psychology syllabus and assumed a prominent position in the agenda of psychological research. (It was, in the r930s and 1940s, joined by clinical psychology and the academic adaptations of psychoanalysis.)

The professional personnel manager and the university-trained psychologist naturally had a vested interest in the cultivation of these practices, and the apparent success of the Taylor movement on the physical side of the management of industrial labor power also produced a conviction in the employer that it was in every respect to his advantage. It was efficient and therefore profitable; it was scientific and therefore modish; and it appeared also by its reliability to divest him of weighty moral responsibilities.

Such was the situation as it developed in the United States from the last decade of the nineteenth century. Class antagonism, increased disrespect for authority, the growing sophistication of academic psychology, and the growth of literacy throughout the population had resulted in the creation of a number of occupations which specialized in intrusion into personal privacy, and which-as practitioners of any occupation usually do-regarded their activities as morally proper and socially useful. They were, moreover, numerous enough, and they served rich enough and powerful enough interests, for them to impose themselves at the margins of public consciousness as pillars of society.

The period since the end of the Second World War has witnessed a powerful reinforcement of those hitherto well accepted and generally uncriticized intruders. 
The war itself, and the Cold W.ar which followed it, created new organizations of specialists in intrusions and new arguments for their indispensability.

Espionage and counterespionage flourished on public funds as never before. The Office of Strategic Services, Military Intelligence, the Federal Bureau of Investigation, and, later, the Central Intelligence Agency carried on a far-flung and intense activity in acquiring information by clandestine and related techniques; they also trained large numbers of persons in the techniques and technology of intrusion. Released to civilian life after the war, they provided the personnel for numerous investigative agencies. They constituted a stratum of vigorous enterprisers recommending the use of their services to prospective users in many spheres of life. The technology of observation and recording, building on electronics and nuclear physics, shot ahead in a manner completely without precedent. Much of this technology became relatively inexpensively available to private operatives, and espionage and counterespionage organizations.

The preoccupation with "security" provided another motive for intrusion into personal private affairs and the occasion for the formation of another vested institutional interest in the penetration of the private sphere of numerous individuals. The activities of the House Un-American Activities Committee and the Senate Subcommittee on Internal Security forced the administrative branch of the federal government, as well as state governments and private employers-whether or not they dealt with "secrets"- to institute "security checks" on their employees. By this time, academic psychology had advanced further in its diagnostic technology, and parts of it found application in the "security program." A variegated battery of personality inventories, projection tests, and lie detectors was brought into play to guarantee against the employment of persons whose disposition or vulnerability might lead them to disclose "secrets" or to behave "disloyally" in any other way.

The "security program"-governmental and private-gave a further impetus to the development of the occupations concerned to intrude into personal privacy. Familial relationships, friendships, personality qualities, sexual practices, relations with neighbors, recreational preferences-all extending far into the past-became objects of detailed scrutiny.

In the past decade there has been a decline in the intensity of anxiety about security and loyalty, but investigative routines have remained the same. The occupational and political interests are too powerful to permit a discontinuance of an ostensibly perfectly legitimate activity. Those administrators who exercise authority over the persons who have been strained and sifted through the inspection of their past, personal and political, prefer to maintain the system as it is. Even if they do not believe completely in its efficacy or pertinence, they have become used to it and they now regard it as part of the natural order of things. They also do not wish to risk criticism from politicians on a question on which they have no strong feelings. 
Furthermore, those who are subjected to this privacy-invading scrutiny do not object or, if they do object, they are without influence.

On top of all this comes the factual hunger of all government bodies. As the range of government activities widens, and as they reach more deeply into the structure of society, government departments gather more and more information about the persons for whom they provide services or whom they seek to control. There is nothing new in these information-gathering activities as such. Governments have always sought to obtain information about their subjects-the Roman census, the Anglo-Norman Domesday Book, and the Nuremberg and Swiss cantonal censuses of the fifteenth century are illustrative of the antiquity of governmental information-gathering. When the modern liberal order was envisaged by the Benthamite radicals in Great Britain early in the nineteenth century, inspection and reporting were the devices they foresaw to discover the effectiveness of reformative legislation. The interest of a government in examining its society in a matter-of-fact way and in publishing reports of what is observed testified merely to its interest in framing its policies in an enlightened way and in enlightening public opinion regarding the grounds and the efficacy of its decisions.

These considerations are still of great influence in the government's informationgathering. Two developments have intervened since the early nineteenth century. The first is the wealth of governments, coupled with the present-day belief in the central importance of social science research. Governments can now employ many persons with social science training and interests. For these persons, gathering information is a legitimation of their existence. With the mighty resources of the government at their disposal, it is only natural for them to collect all the information they can, particularly since it can be justified by the needs of rational administration, control, and service.

From this assembly of facts by various government departments, it is only a step, which some have already proposed, to the collation of all the information gathered about each individual into a computer-equivalent of a dossier. It is all conceived with innocent intentions, as if it were both necessary and just that each individual member of society should be exhaustively known by the government. They have in mind no particular or immediate use for these computer "dossiers." They just think that it is a "good idea" to have them-so far have they strayed from respect for privacy.

Another factor in making it appear normal and necessary to collect, both openly and clandestinely, personal private information is the "dishonesty crisis" in industry. Thefts by employees have been regarded as on the increase, as has the divulgence of industrial secrets. Since ordinary police practices were inadequate, the testing of prospective and present employees was adduced as a supplement. In addition, other methods of gathering information were applied in an effort, which has not been 
notably successful, to halt the ravages of the "dishonesty crisis." The very persistence of the crisis is deemed a justification for further intrusions into privacy.

The development of empirical social research in the period since the Second World War is relevant to our consideration of the vicissitudes of privacy in contemporary society. Ever since sociology became an empirical subject, it has lived in the presence of the privacy of the persons it studied. The technique of participant-observation involved the possibility of intrusions into personal privacy by direct interrogationas does the contemporary survey technique. It also permitted, through long dwelling in the community studied, considerable observation of personal private actions which the person observed did not intend to disclose. As far as I can recall, until about I955 there was never any question of the ethical status of this sort of research. It was generally understood that the anonymity of particular informants was to be observed, but nothing more was required.

The shift away from participant-observation toward sample surveys as the main mode of sociological field work has been attended by a much more penetrating inquisitiveness into the personal private sphere. This is partly the result of psychoanalysis, which commended to the attention of sociologists phases of conduct with which they had not previously dealt. The progress and enlarged self-confidence of sociologists have also encouraged this, as well as the greater impersonality of the new techniques. The new techniques of sociological research, by restricting the tie between the investigator and the person investigated, have reduced inhibitions against intrusion into personal privacy. The absence of a personal relationship between investigator and the investigated weakened the barriers to penetration and intrusion which the quasi-personal ties in some way supported. ${ }^{10}$ The partial dissolution of traditional inhibitions regarding discussion of sexual practices opened a whole new front of intrusion into the personal private sphere. What was once prurience and voyeurism has now become "scientific curiosity." What was once "exhibitionism" is now cooperation in "scientific research." What was once regarded as the subject of "blue films" and "circuses" is now called a "research situation." The result is the same-an invasion of personal privacy of an extreme character, more elaborate and naturally better documented than its pre-"scientific" predecessors.

Such effectiveness as the police have had in dealing with those who repeatedly commit crimes was always to some extent a result of their intimate knowledge of the "criminal underworld." Through long experience and the accumulation of knowledge of the habitual practices of criminals and through "informers," the police came to know a great deal about the personal private affairs of criminals. They had no compunction about obtaining and using such information to trace criminals; there was little or no objection from the law-abiding public about these procedures.

\footnotetext{
${ }^{10}$ Of course, unlike the popular press, its disclosures are not given personally identified and wide publicity. And unlike the disclosures of the "security" services, they are not given "secret publicity," i.e., arcanic circulation within authoritative bodies.
} 
Then came the revolution in communications technology: telephone tapping, the recording of conversations, the "bugging" of places where criminals gathered, long distance photography, and so on. The police were not the first to use such techniques, but once their effectiveness was demonstrated the police too began to use them. The increased resourcefulness and the undiminished daring of criminals placed the overworked and understaffed police in a position in which they were at a disadvantage vis-d-vis the criminals if they did not use some of the newer techniques. Even now, however, it does not seem as if the police are the major intruders into personal privacy. Much more of it is done by the national security services, by private operatives, and by the mass communications-both the press and the television.

In our review of the institutional organization of privacy intrusion in the middle of the twentieth century, a word must be said on the investigation of credit-worthiness. The rising standard of living and the increased demand for an even higher standard of living has given a tremendous impetus to installment buying and purchase on the basis of bank loans, loans from money-lenders. All of this has again involved the acquisition by private investigative agencies of a considerable amount of personal private information about resources, spending habits, and so forth, of individuals and families. (There is no code of ethics among those who acquire this information to use it only for the particular purpose for which it has been acquired. Either gratuitously or for a small charge they will make this information available to other investigative agencies.)

Closely allied to this system of investigation of retail purchasers is the elaborate system of promotion which is based on another form of privacy-intrusion. It is a common practice in the United States for firms having a list of names of customers to sell that list to any other firm wishing to pay for it. In consequence, many individuals who have made a purchase from one firm are placed in a position where their privacy is intruded upon by solicitations, usually by post and less frequently by personal intervention or by telephone, on the part of other firms in the hope of persuading them to make still another purchase in which they have never indicated any interest.

Finally, a few words should also be said about a major development in the theory of personality which has found application in or legitimated numerous of the more recent forms of intrusion into personal privacy. This is the idea of the personality as a system.

The idea of the unity or wholeness of the human personality is an old one, but it has become the object of research and the basis of manipulative actions only relatively recently. Instead of the idea of separately functioning sectors of the individual personality, there gradually took form the idea that all the various functions were interconnected; from this postulate the hypothesis was derived that small and apparently insignificant pieces of conduct could be interpreted as indicative of those 
more important states of the individual's personality and propensities for action which could not be directly observed. The psychoanalytic theory of the psychic economy; the "psychoanalytic interpretation of everyday life," according to which tics, gestures, slips of the tongue, and so forth, express dispositions; and the word-association test, which was developed by Jung on this presupposition, were each a contribution to a mode of diagnosis according to which visible and elicitable actions permitted inferences about interior dispositions and impulses which would determine future actions. The psycho-physiological unity of the personality system is also the presupposition of the "lie detector" test. Employers and their personnel managers and security officers were eager beneficiaries of these techniques which would enable them to discover and select those persons whose impulses, as disclosed by such tests, would eventuate in loyal, efficient, and cooperative conduct.

\section{VI}

In the course of the past quarter century, certain trends in intrusion into personal privacy that date back to the last part of the nineteenth century have been accentuated. The increase that we have noted has been the accomplishment mainly of certain sectors of the elite of our society among the highly educated and literate and those who occupy authoritative roles. Intrusions into privacy have been so intertwined with the pursuit of objectives that are unimpugnable in our society, such as freedom of the press, the protection of public order, the prevention of subversion, the protection of private property, and industrial and administrative efficiency, that each extension of the front has been accepted as reasonable and useful. Each objective has appeared, to large sectors of the elites at the center of society, to be well served by the particular form of intrusion into personal privacy that their agents have chosen for the purpose.

The movement has not been all in one direction. Certain sections of the legal profession, the judiciary, and legislative bodies have repeatedly attempted, since the end of the Second World War, to restrict and diminish the amount of intrusion into personal privacy. In the past few years, the enormities of intrusion have activated a quite new concern to protect personal privacy. But the resistance thus far is largely an elite resistance.

We live in a society that is often called a "mass society" and in which the demands of the "masses" are said to be decisive in determining the character of the society. To what extent have the masses been responsible for the intrusions into privacy? They have not initiated them. Governments, journalists, employers, and social scientists have been the main intruders into personal privacy. The masses have, however, accepted these intrusions both into their own personal privacy and into that of others. They have accepted the excesses of the security programs in government and private industry with negligible objection. They do not feel themselves con- 
tinuously under scrutiny-once cleared, the matter is settled, and in most instances they know little of what is going on. And they show little solicitude for those who are not cleared. It is believed that the practices are justifiable because they are allegedly designed to catch the disloyal and subversive. As for the disloyal and the subversive, they have no rights and no one should complain when they are affronted.

As regards the doings of private operatives, most people do not come under their scrutiny, and if they do they seldom know it. There is a belief that only wrongdoers and potential wrongdoers attract the attention of private operatives, and they, like those who are allegedly or potentially subversive or disloyal, have no rights which need be considered.

Nor do the intrusions of the popular press and certain television features arouse any moral condemnation; on the contrary, they are rather enjoyed.

The enrichment of the advanced modern societies of the Western world has made possible an increase in leisure time; it has nurtured an increased hedonism, an increased desire for pleasure. Increased leisure and the increased desire for pleasure on the part of persons without either sufficient education or sufficient intelligence to extend the radius of their interest or imagination beyond their neighbors, beyond the personal onto a more transcendent level, or to find gratification in the reading of fictional accounts of personal private lives, have engendered a demand for allegedly real accounts of the personal private lives of real persons who live in the center of society, who are influential and creative. Television programs and popular magazines include among their repertoire personal portraits, interviews which ask questions about personal private matters, explorations of the private affairs of public figures in the entertainment and political worlds. "Candid cameras" are regarded as perfectly legitimate-at least one has heard no charges of impropriety against them. The intimacies of other persons are "interesting," and where they are degrading to the mighty and great, they are all the more acceptable. The embarrassments of those who have discomfiting disclosures made about them are as attractive as a boxing match.

Intrusions into personal privacy are part of the currency of present-day society. Even though the government's intrusions, because they are usually held secret or confidential by their official custodians, do not give the pleasure that is given by those in the media of the press, daily and periodical, and the television, they are accepted as having the same legitimacy as laws, taxes, and trade union fees. They are regarded as not necessarily agreeable but probably right and in any case inevitable.

The belief in American society that the personal privacy of other persons should be acknowledged and protected does not have a very strong or principled adherence among the lower middle and working classes. There is, indeed, a welcoming of the opportunity to share in the knowledge made available by breaches in the barriers 
around it. There is little resistance to infringements on one's own privacy, particularly as long as the information so obtained does not circulate widely and as long as it does not involve clandestine and coercive intrusion into private spaces. ${ }^{11}$ In the case of many persons and for many types of personal actions, a wide diffusion through television or press is welcomed. Most individuals do not wish any disclosure of personal private actions which might be derogatory to themselves to be widely circulated, but about more neutrally assessed intimacies they have much less reluctance. In fact, they prefer a certain amount of publicity, not because they think that their private actions will evoke admiration, but because they enjoy the act of sharing or communion with a very large circle-at least for a short period. Perhaps they would not wish to have all their actions-even those which are not morally reprehensibleexhibited to a boundless audience; but, as an occasional variation from a state of unregarded obscurity, it is welcome.

Nonetheless, all these complaisances notwithstanding, and despite this enfeeblement of the ethos of "respectability," there also persists among the citizenry of contemporary America, as well as in other countries, a belief that "one should keep one's own counsel," that the family next door should not know all that goes on within the walls of one's own dwelling place. There is reluctance, even repugnance, about having one's own telephone conversations listened to by other persons, known or unknown to the speaker-and that quite apart from any harm that might be done by the eavesdropper. There is still disapproval of tale-bearing gossips, and there is a modicum of respect for the privacy of those with whom one associates in face-toface relationships.

What is the relationship between the reserve just referred to, the readiness to accept and even to welcome disclosures about one's own personal private affairs, and the rather considerable indifference to infringement on the privacy of others? These diverse and discordant tendencies stand in a complex relationship to each other, and it is difficult to do them justice analytically. The few hypotheses that follow are asserted with much hesitation.

There is more insistence on privacy before those whom one "knows," i.e, those whose names are known and whose presence is frequent, than before anonymous entrants into the private sphere, especially when they enter following even a simulacrum of assent. This is so in the case of the interviewee in a research relationship or the applicant for private or government employment. There is at least that much acknowledgment of the rights and bona fides of authority. There is also a greater readiness to accept an intrusion into the private sphere where the intruder supplies an at least nominal guarantee that the information disclosed about private things will not be openly or widely circulated. An assurance of "secrecy" or "confidentiality" is often

\footnotetext{
${ }^{11}$ Many persons seem to take the view that television surveillance of the behavior of employees within a factory or office comes within the prerogative of the employer, since it is the employer's private space. Protests originate more often among trade union officials.
} 
regarded as a wholly acceptable condition for the admission of an intruder into one's private sphere.

But the fact remains that participation in the disclosure of the personal private affairs of others, where it is not an object of intense exertion on the part of the recipient, has an appreciative audience. Few indeed are those who will adamantly refuse to hear about the personal private affairs of others whom they know or know about. Whether it is out of desire for a wider conviviality or for the degradation and humiliation of a fellow human being, the entry, on one's own initiative or through the intrusive action of others, into other persons' personal private affairs is one of the features of human society. ${ }^{12}$

The point is that, quite apart from the ecological dependence of human beings on each other, they cannot sustain a great deal of privacy. They do not wish to be contained within the boundaries defined by those whom they know personally and with whom they are in relations of intimacy and mutual confidence. They wish to extend the scope of their existence through the exercise of their imagination. For those who lack the creative power to spur their imaginations, the personal private affairs of the fellow men whom they know and of the eminent persons at the center of society offer more easily available sustenance for this need to extend the scope of their existence.

Nor do they want always to keep within themselves. They want to extend themselves by sharing with others what they know of themselves. Sometimes they wish to share this knowledge with particular persons, and the act of sharing also simultaneously erects a boundary which separates the community of the sharers.

They want to share in privacy. This paradoxical combination of control over what belongs to the self and its transcendence in a relationship of sharing runs throughout the whole complex of the phenomena which are subsumed under the term "privacy." That which is solitarily private is often impelled outward into a community of two persons; that which is personally private between two persons is often impelled outward into a sharing between one of the two and a third person, and so it goes-but nearly always with the intention that it should not pass beyond that

${ }^{22}$ This willingness and even desire to know about the personal private affairs of others might be functions of certain fundamental qualities of human beings in contemporary society. We refer here to the increased individuality and the increased empathic capacity and needs of the expansive ego characteristic of an individualistic and open society.

First of all, it should be said that the growth of individuality has contributed to the demand for privacy. The awareness of self, of the uniqueness of the self, makes for a greater sensitivity to impingement on self, to intrusion into the zone around that self. Individuality makes for spontancity and the prizing of relationships spontaneously entered into and maintained by a mutuality of spontaneously flowing sentiment. Such relationships generate a demand for privacy, since they feel the alien character of intruders who cannot produce the affirmative spontancity necessary to a proper participation. But the growth of individuality has a dialectical relationship to privacy. Individuality has provided a neccssary condition for empathy.

Empathy entails a sense of affinity with the mind and state of feelings of other individuals. But the empathic capacity also brings with it the desire to enter the mind and the desire to know what is there. 
third or $n$th sharer. Voluntary self-disclosure is not usually intended to be boundless. The disclosure does not entirely annihilate the boundedness characteristic of privacy.

The desire for privacy is nearly always partial. There is a desire to be simultaneously in private and in "public" relations with particular other persons. Thus not everything is shared with those with whom certain things are shared. Certain private matters might be shared with some persons; other private things might be shared with other persons.

\section{VII}

The present concern for privacy does not rest on the belief that every individual or that every primary group must be a windowless monad. Communion is a good as much as individual autonomy. Self-transcendence is as essential to man's existence as the dignity of selfhood or individuality. The present concern for privacy does not absolutize privacy.

It is also to be recognized that the personal privacy of individuals and groups among their peers and intrusions into personal privacy among peers are not a great issue. Personal privacy among peers is as strongly entrenched as most individuals who possess it wish to make it. And in so far as it is not, most of the intrusions, which do not involve the new technology of intrusion, are beyond the bounds of control. At least they cannot be controlled by anyone except the persons or groups whose personal privacy is intruded upon.

Privacy has become a problem in the past few decades not because the human race has gone mad and wishes to renounce a valuable feature of existence. On the contrary, there is still a great deal of attachment, both in daily practice and in principle, to privacy, and that attachment is perhaps not less, and is perhaps even more, than in previous times.

Privacy has become a problem because it has become engulfed in the expansion of the powers and ambitions of elites and in the difficulties that they encounter in attempting to govern and protect and please vast collectivities. ${ }^{13}$

It is not that some of these intrusions into personal privacy are not necessary and justified. The tasks which the electorate wishes modern governments to perform do require much information; industrial enterprises must seek to be efficient; the mass media must entertain as well as enlighten; public order must be established and maintained and subversion prevented; systematic empirical study of human society must be cultivated. Nonetheless, even though one grants that the common good cannot be realized in a society consisting only of private entities and that the common good requires some restrictions on the right of privacy, one is also impressed that

\footnotetext{
${ }^{18}$ I mention elites, private and public, even though I am aware of the obnoxiousness of the numerous private detective agencies. The depredations committed by these against personal privacy are done either at the behest of industrial and commercial employers or because of the unsatisfactory state of divorce laws. If these two sources of support of the private detective agencies were reduced, the work of these agencies would still remain a nuisance but only a minor one.
} 
many justifications in terms of the common good in very many of the instances of intrusion into privacy are mendacious in the extreme. A great deal of the intrusion into personal privacy is not only an immoral affront to human dignity, it is also quite useless and unnecessary from any serious standpoint. Much of it is unnecessary to effective government, efficient administration, national security, the progress of knowledge, or industrial productivity. Much of it is the frivolous self-indulgence of the professionals of intrusion.

When we contend for privacy in contemporary society, it is not that we are anxious lest all privacy be obliterated. That is not the problem. Obviously, each individual will always be private to most other people in his society; and even when his personal private affairs are penetrated, the knowledge so gathered will not be universally diffused. Such extreme possibilities are of no relevance to our discussion because they are so improbable.

The significant intrusions affect either small numbers of individuals whose personal privacy is intruded upon because they are allegedly of "public interest," or because an ill-wisher seeks to "get something on" them. Or else they affect large numbers, although segmentally; some authorities wish to be assured of their capacity for acting efficiently and loyally on behalf of the interests of those authorities.

Sometimes harm is done by these intrusions. Individuals are made unhappy and occupational opportunities are denied them. Sometimes it can be argued that they are injured financially by such intrusions. But these considerations appear to be of secondary importance. Intrusions on privacy are baneful because they interefere with an individual in his disposition of what belongs to him. The "social space" around an individual, the recollection of his past, his conversation, his body and its image, all belong to him. He does not acquire them through purchase or inheritance. He possesses them and is entitled to possess them by virtue of the charisma which is inherent in his existence as an individual soul-as we say nowadays, in his individuality-and which is inherent in his membership in the civil community. They belong to him by virtue of his humanity and civility. A society that claims to be both humane and civil is committed to their respect. When its practice departs from that respect, it also departs to that degree from humanity and civility. 